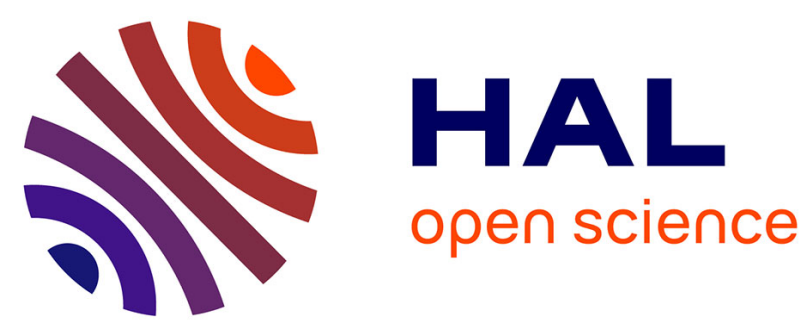

\title{
Thin layer etching of low-k SiCO spacer using hydrogen ion implantation followed by hydrofluoric acid
}

Nicolas Posseme, Maxime Garcia-Barros, François Leverd, Daniel Benoit, Olivier Pollet, Guillaume Audoit, Cyril Guedj, Audrey Jannaud, S. Barnola

\section{- To cite this version:}

Nicolas Posseme, Maxime Garcia-Barros, François Leverd, Daniel Benoit, Olivier Pollet, et al.. Thin layer etching of low-k SiCO spacer using hydrogen ion implantation followed by hydrofluoric acid. Journal of Vacuum Science \& Technology B Microelectronics and Nanometer Structures, 2018, 36 (5), pp.052201. 10.1116/1.5038617 . cea-02185184

HAL Id: cea-02185184

https://hal-cea.archives-ouvertes.fr/cea-02185184

Submitted on 8 Apr 2020

HAL is a multi-disciplinary open access archive for the deposit and dissemination of scientific research documents, whether they are published or not. The documents may come from teaching and research institutions in France or abroad, or from public or private research centers.
L'archive ouverte pluridisciplinaire HAL, est destinée au dépôt et à la diffusion de documents scientifiques de niveau recherche, publiés ou non, émanant des établissements d'enseignement et de recherche français ou étrangers, des laboratoires publics ou privés. 


\title{
Thin layer etching of low-k SiCO spacer using hydrogen ion implantation followed by hydrofluoric acid
}

\author{
Nicolas Posseme, ${ }^{1, a)}$ Maxime Garcia-Barros, ${ }^{2}$ François Leverd, ${ }^{2}$ Daniel Benoit, ${ }^{2}$ \\ Olivier Pollet, ${ }^{1}$ Guillaume Audoit, ${ }^{1}$ Cyril Guedj, ${ }^{1}$ Audrey Jannaud, ${ }^{3}$ and S. Barnola ${ }^{1}$ \\ ${ }^{1}$ CEA LETI-Minatec, 17 Avenue des Martyrs, 38000 Grenoble, France \\ ${ }^{2}$ ST Microelectronics, 850 Rue Jean Monnet, 38920 Crolles, France \\ ${ }^{3}$ Serma Technologies, Minatec Campus, 38040 Grenoble, France
}

(Received 4 May 2018; accepted 13 July 2018; published 10 August 2018)

\begin{abstract}
Spacer etching realization is considered today as one of the most critical processes for the fully depleted silicon on insulator devices realization. The challenge arises from the fact that low-k spacer needs to be introduced to improve device performances. In this paper, a new approach to etch the low-k SiCO film was investigated. This approach is based on the SiCO film modification by $\mathrm{H}_{2}$ plasma followed by a removal step of this modified layer using hydrofluoric acid- (HF) based wet cleaning. It has been demonstrated that $\mathrm{SiCO}$ layer modification depth is controlled by plasma parameters like bias voltage. The SiCO film modification induced by $\mathrm{H}_{2}$ plasma has been well understood by x-ray photoelectron spectroscopy, infrared spectroscopy analyses in transmission or in multi-internal reflection. It has been demonstrated that the $\mathrm{H}_{2}$ plasma exposure converts the SiCO film in volume into an $\mathrm{SiO}_{\mathrm{x}} \mathrm{H}_{\mathrm{y}}$ film, explaining the higher damaged film removal rate when dipped in liquid phase HF. Finally, the compatibility of the new etch approach with the SiCO low-k film has been demonstrated on pattern structures. Published by the AVS.
\end{abstract}

https://doi.org/10.1116/1.5038617

\section{INTRODUCTION}

With aggressive device shrinking, parasitic capacitances through the spacer become an important contributor to the total device capacitance. This issue is exacerbated by the common use of silicon nitride ( $\mathrm{SiN}$ ) spacers since $\mathrm{SiN}$ has a relatively large dielectric constant $(\mathrm{k} \sim 7.5)$. A simple approach to reduce capacitive coupling through the spacer is to replace it with a low-k material. ${ }^{1}$ Therefore, the reduction of the spacer $\mathrm{k}$ value is a key for the high performance devices.

In this context, low dielectric (low-k) constant films like $\mathrm{SiOCN}, \mathrm{SiCBN}$, or SiCO have been proposed in the literature to replace the traditional silicon nitride. ${ }^{2-4}$

But the introduction of these materials leads to critical patterning issues. Such low-k films are much more sensitive to fluorocarbon-based chemistries generally used in fully depleted silicon on insulator technology allowing pattern dimension control and selectivity to the underlying ( $\mathrm{Si}$ or $\mathrm{SiGe}$ ) layer. ${ }^{5}$ For example, the spacer low-k film can be isotropically etched using $\mathrm{CH}_{3} \mathrm{~F} / \mathrm{O}_{2} / \mathrm{He}$ plasma leading to a difficult critical dimension $(\mathrm{CD})$ control during the etch process (Fig. 1).

In another case, a full film modification of the low-k film, occurring during the plasma etching process, can lead to a complete removal of this film after hydrofluoric acid (HF) (pre clean epitaxial step), as shown in Fig. 2.

These difficulties impose to optimize the current etch chemistry to be compatible with low-k spacers.

An original etching approach has recently been reported for silicon nitride spacer etching. It consists of anisotropical modification of the silicon nitride film by $\mathrm{H}_{2}$ or $\mathrm{He}$ plasma performed in an inductively coupled plasma (ICP) or a

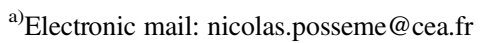

capacitively coupled plasma etch tool and then selectively removing the modified fraction of the layer with hydrofluoric acid dip, ${ }^{5}$ vapor $\mathrm{HF},{ }^{6}$ or $\mathrm{NH}_{3} / \mathrm{NF}_{3}$ (Ref. 7) remote plasma. It has been demonstrated that layer modification depth is controlled by plasma parameters, like bias voltage, source power, and process time. The benefit of this unconventional technique was demonstrated on $14 \mathrm{~nm}$ fully depleted silicon on insulator logic device and showed less than $1 \mathrm{~nm}$ silicon nitride spacer CD loss, less than $0.6 \mathrm{~nm}$ SiGe recess which enabled defect-free source/drain epitaxy. ${ }^{8}$

In this paper, we propose to investigate the compatibility of this new approach with the etching of SiCO. This low-k film modification has been analyzed by $\mathrm{x}$-ray photoelectron spectroscopy (XPS), and infrared spectroscopy analyses in transmission (T-FTIR) and multiple internal reflection (MIR-FTIR).

Finally, the SiCO film etching has been evaluated on patterned structures.

\section{EXPERIMENT}

\section{A. Material investigated}

We have used $300 \mathrm{~mm}$ diameter silicon wafers coated with the $30 \mathrm{~nm}$ SiCO film deposited by chemical vapor deposition (CVD) for the blanket film study. The low-k spacer $(\mathrm{k}=4.5)$ is deposited at $400^{\circ} \mathrm{C}$. More details about this film can be found in a previous paper. ${ }^{9}$

The etch process developed on the blanket wafer has been validated on patterned wafers using the stack described in Fig. 3. After gate etching using conventional etch chemistry, a conformal SiCO $(10 \mathrm{~nm}, \mathrm{CVD})$ is deposited around the gate. The $\mathrm{SiCO}$ is then anisotropically damaged by $\mathrm{H}_{2}$ 


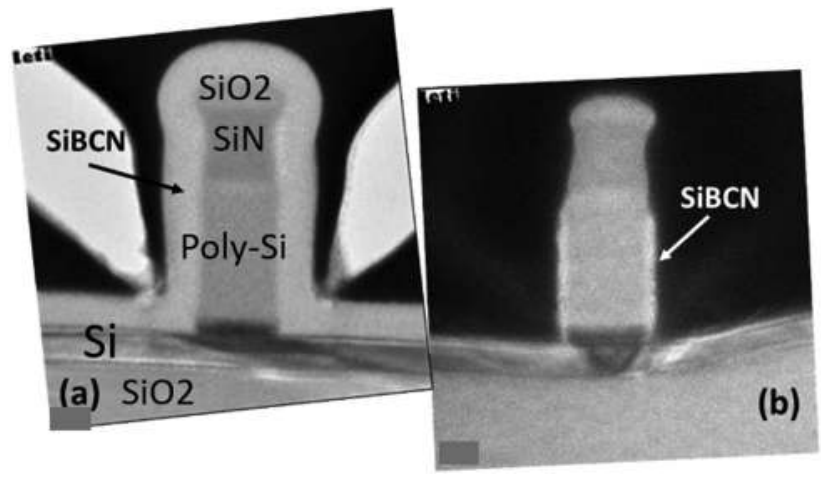

FIG. 1. TEM pictures of $12 \mathrm{~nm}$ SiBCN conformal deposition by PECVD (a) followed by the conventional etching step using $\mathrm{CH}_{3} \mathrm{~F} / \mathrm{O}_{2} / \mathrm{He}$ chemistry performed in an ICP plasma etch tool (b).

plasma (Sec. II B 1) followed by a selective removal of the modified layer by HF (1\%). Finally, $0.1 \% \mathrm{HF}$ preclean is performed before the epitaxy of the $20 \mathrm{~nm}$ SiGe raised source drain.

\section{B. SiCO film etching}

\section{SiCO film damage by $\mathrm{H}_{2}$ plasma}

The $\mathrm{H}_{2}$ plasma damage experiments have been performed in a $300 \mathrm{~mm}$ Kiyo CX ICP etch tool from LAM Research. The plasma is excited inductively via an antenna $(13.56 \mathrm{MHz})$. The chuck is powered with an RF generator operating at $13.56 \mathrm{MHz}$. Chamber cleaning and wall coating (using $\mathrm{SiCl}_{4} / \mathrm{O}_{2}$ ) are performed between each wafers in order to get reproducible etch/modification conditions.

Three hundred millimeter diameter wafers are clamped using an electrostatic chuck. The temperature of the wafer is kept at $50{ }^{\circ} \mathrm{C}$ by helium backside cooling, whereas the top electrode with the gas shower head was maintained at $90{ }^{\circ} \mathrm{C}$. In our experimental conditions, when not mentioned, the pressure, bias voltage, plasma power, gas flow rate, and process time are set at $10 \mathrm{mTorr}, 250 \mathrm{~V}, 500 \mathrm{~W}, 50 \mathrm{sccm}$, and $60 \mathrm{~s}$, respectively.

In the following, when the $\mathrm{SiCO}$ film is modified by $\mathrm{H}_{2}$ plasma, it will be labeled as $\mathrm{SiCO}^{*}$ to distinguish it from unmodified SiCO.

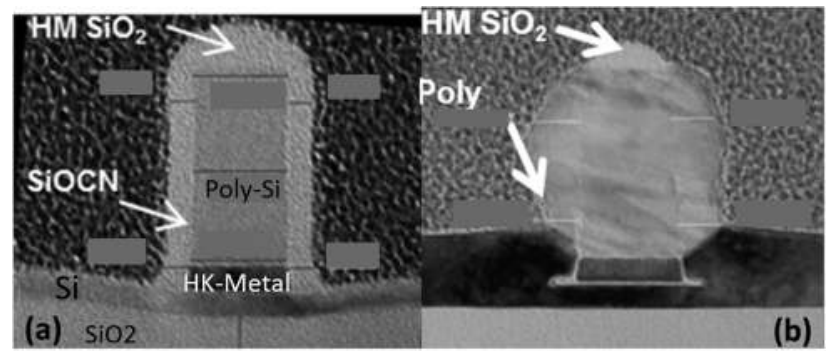

FIG. 2. TEM pictures after the low-k SiOCN etching using $\mathrm{CH}_{3} \mathrm{~F} / \mathrm{O}_{2} / \mathrm{He}$ chemistry performed in an ICP etch tool (a) followed by an HF dip preclean and epitaxial growth (b).

\section{SiCO film damage removal by HF dip}

The modified layer is removed by a cleaning step using a Raider single wafer from AMAT. The wafer is loaded in a spray acid chamber where it is processed face down. Wafer is spun at a controlled speed and chemical is sprayed through a nozzle manifold at $90^{\circ}$ incidence. After the chemical step, wafer is rinsed inside the chamber and dried by means of vapor IPA.

\section{Film modification characterization \\ 1. Spectroscopic ellipsometry}

The SiCO film thickness has been measured by ellipsometry with an ALERIS HXTM setup from KLA TENCOR ${ }^{\text {TM }}$ for an incident angle of $71^{\circ}$. A Cauchy transparent model has been created for thickness measurement from wavelengths between 157 and $895 \mathrm{~nm}$. The pristine SiCO thickness is estimated to be $30 \mathrm{~nm}$ on the blanket wafer.

\section{X-ray photoelectron spectroscopy}

Surface etching mechanism phenomena have been understood by ex situ XPS experiments. The experiments have been carried out on a Thermo Fisher Scientific Theta 300 spectrometer operating with a monochromatic $\mathrm{Al} \mathrm{K} \alpha$ x-ray source $(h v=1486.6 \mathrm{eV})$. This system allows parallel angle resolved x-ray photoelectron spectroscopy with a probed depth ranging from 0 to $10 \mathrm{~nm}$ below the surface. The concentrations of $\mathrm{C}, \mathrm{Si}$, and $\mathrm{O}$ atoms are extracted from the $\mathrm{C} 1 \mathrm{~s}$,

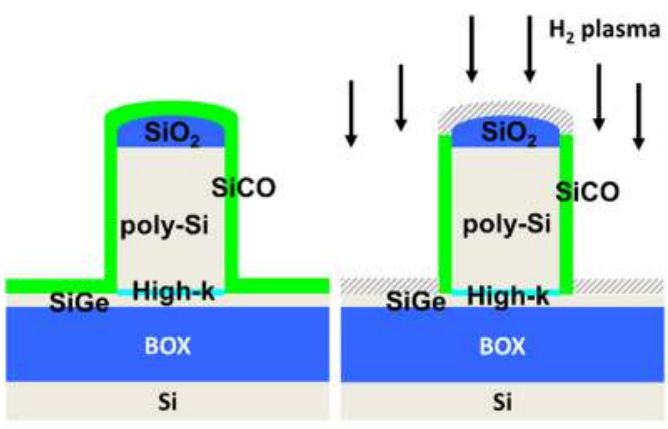

(a)

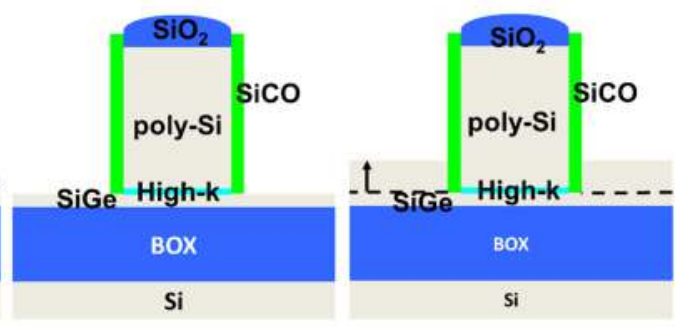

(b)

(c)

FIG. 3. Description of nitride spacer etching using an alternative approach based on two steps: $\mathrm{H}_{2}$ plasma (ICP) (a) followed by the selective removal of the modified layer using HF $1 \%$, (b) followed by $30 \mathrm{~s} 0.1 \% \mathrm{HF}$ etch, and growth of $20 \mathrm{~nm}$ of SiGe by epitaxy (c). 
Si2p, and O1s core level energy regions, respectively. Chemical compositions are estimated from the areas of the respective XPS contributions using AVANTAGE ${ }^{\mathrm{TM}}$ software. Spectral fitting conditions have already been described in a previous paper. ${ }^{7}$

XPS measurements have been carried out for 10 scans with a dwell time of $500 \mathrm{~ms}$ and a pass energy of $50 \mathrm{eV}$, giving a $1 \mathrm{eV}$ spectral resolution. The analyzed surfaces are measured at eight take off angles equally spread between $23.75^{\circ}$ and $76.25^{\circ}$ relative to the substrate normal. In this paper, we have focused on the less grazing incidence $\left(23.75^{\circ}\right)$.

Since the materials analyzed are quite insulating, electrostatic charging effects generate an energy shift of the recorded XPS peaks. A flood gun has been used to compensate this charging (filament $2.1 \mathrm{~A}$, extraction $40 \mathrm{~V}$, and emission $150 \mu \mathrm{A})$.

\section{Infrared spectroscopy}

T-FTIR and MIR-FTIR were performed using a Bruker IFS-55 Fourier transform infrared spectroscopy (FTIR) spectrometer.

For the T-FTIR analyses, the IR beam passes through the wafer and is focused on an MCT detector. The T-FTIR mode covers a spectral range from 600 to $400 \mathrm{~cm}^{-1}$.

For the MIR-FTIR analyses, the sample is coupled to the s-polarized IR with two silicon prisms with the spacing adjusted to $Z=6 \mathrm{~cm}$. An s-polarized IR beam coming from an FTIR spectrometer is directed on the coupling area of the input prism, which ensures optical tunneling inside the wafer. After being internally reflected about 100 times in our conditions (with an incidence angle of $34^{\circ}$ and a wafer thickness of about $600 \mu \mathrm{m}$ ), the IR beam is coupled out of the wafer by the second prism and focused onto a liquid- $\mathrm{N}_{2}$-cooled HgCdTe detector. ${ }^{10,11}$ The MIR technique is 100 times more sensitive than the standard transmission mode (T-FTIR). The IR beam propagates inside the wafer; so, the samples have to be double-side polished. The MIR-FTIR mode covers a spectral range from 2000 to $4000 \mathrm{~cm}^{-1}$.

Spectra are recorded with a $2 \mathrm{~cm}^{-1}$ spectral resolution and an average of 32 and 200 scans with the T-FTIR and MIR-FTIR modes, respectively. For both modes, a reference spectrum is measured using an uncoated silicon wafer in order to remove the spectral contributions of the silicon wafer and the optical bench. The baseline of IR spectra is removed with the software "RESOLUTION PRO" using the "spline" method. The "force" option displaces the points of the baseline, placed by the user manually, vertically exactly on the curve.

\section{RESULTS AND DISCUSSION}

\section{A. Plasma parameter impact on SiCO depth modification}

\section{Implant depth estimation}

$\mathrm{SiCO}$ and $\mathrm{SiCO}^{*}$ films have been exposed to different times of $\mathrm{HF}$ in liquid phase (method already described to

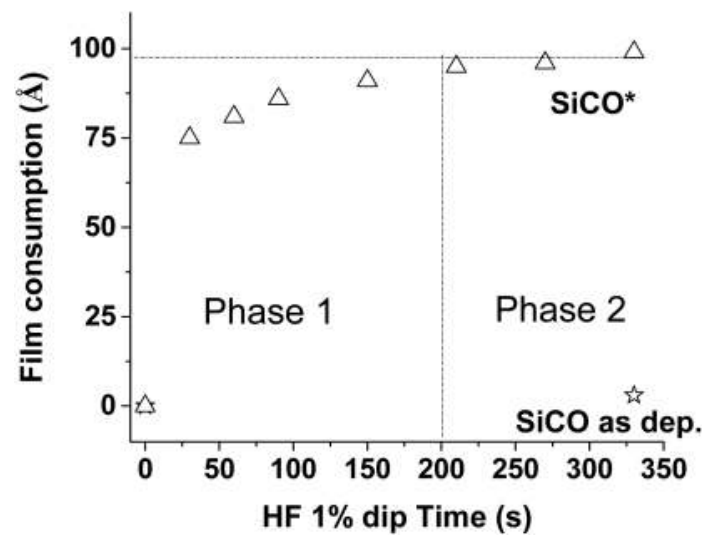

FIG. 4. Evolution of the $\mathrm{SiCO}$ and $\mathrm{SiCO} *$ film consumption as a function of HF dip time.

characterize the SiN film thickness after $\mathrm{H}_{2}$ plasma ${ }^{5}$ ). The etched thickness is presented in Fig. 4 as a function of the HF dip time.

Pristine SiCO is barely etched after $330 \mathrm{~s}$ HF dip time (only $3 \mathrm{~A}$ is consumed), while the $\mathrm{SiCO} *$ shows an increase in the etching rate during the first seconds of HF dip (phase 1) then stabilized after $200 \mathrm{~s}$ to reach a plateau (phase 2). This means that the modified layer is etched during the first phase, while the second phase corresponds to the remaining nonmodified $\mathrm{SiCO}$ film consumption. In our experimental conditions, the modified $\mathrm{SiCO}^{*}$ layer thickness is estimated to be $10 \mathrm{~nm}$.

This behavior is similar to what we have already observed for silicon nitride. ${ }^{5}$ It has been demonstrated that there is a threshold in hydrogen dose above which the layer is modified enough to be etched by the HF $\operatorname{dip}^{5}$ at a significantly higher etch rate than that of pristine SiN.

\section{Ion energy impact on SiCO* film thickness damage}

The impact of the ion energy on the SiCO* modified film thickness has also been investigated by applying a bias voltage between 100 and $400 \mathrm{~V}$. The SiCO film damage

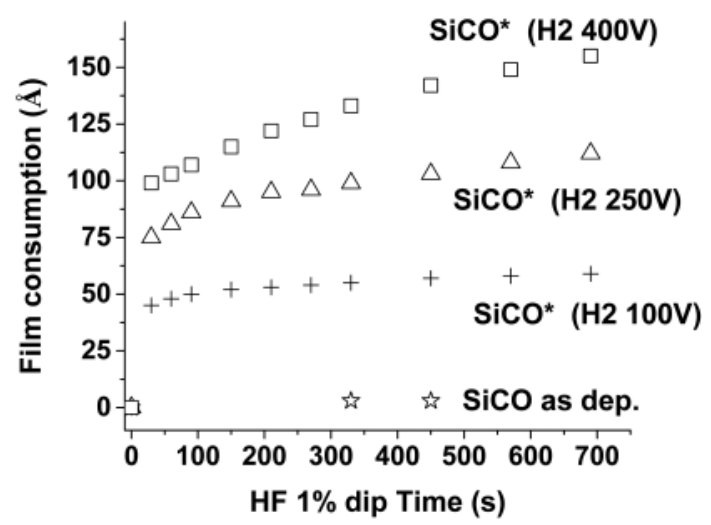

Fig. 5. Evolution of the $\mathrm{SiCO}^{*}$ film consumption as a function of bias voltage and HF dip time. 
consumption has been measured as a function of HF $1 \%$ dip time, and is presented in Fig. 5.

For a $100 \mathrm{~V}$ bias voltage applied during the $\mathrm{H}_{2}$ plasma, the $\mathrm{SiCO}^{*}$ thickness is $\sim 6 \mathrm{~nm}$. Increasing the bias voltage to 250 and $400 \mathrm{~V}$ increases the SiCO* thickness to 10 and 16 $\mathrm{nm}$, respectively.

Therefore, an increase of the ion energy leads to an increase of the SiCO film modification depth which is in good agreement with the previous study performed on the silicon nitride film. ${ }^{5}$

In order to examine if a similar etch mechanism can be drawn for the $\mathrm{SiCO}^{*}$ film, complementary characterization analyses have been performed.
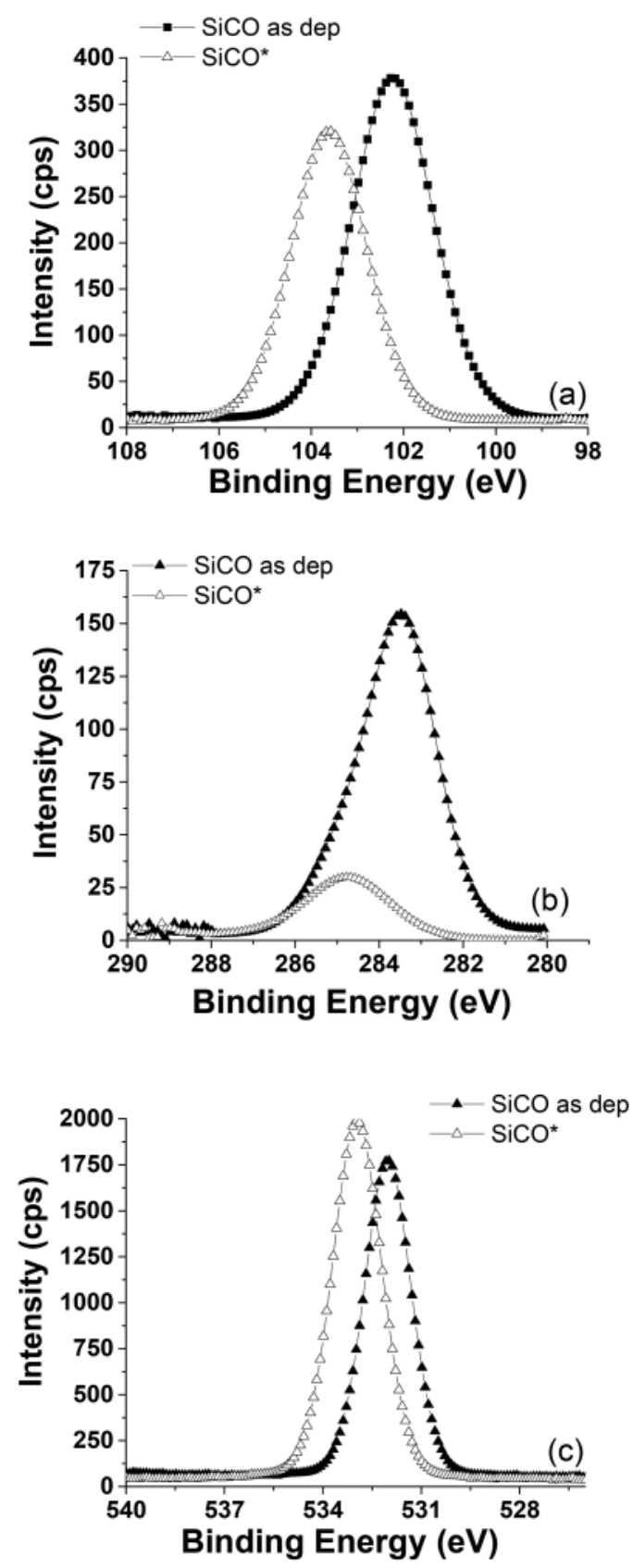

FIG. 6. (a) Si2p, (b) C1s, and (c) O1s spectra recorded by XPS for the as deposited $\mathrm{SiCO}$ and $\mathrm{SiCO} *$ films.

\section{B. Characterization of the SiCO* film}

\section{Film characterization by XPS}

As deposited $\mathrm{SiCO}$ and $\mathrm{SiCO} *$ films have been analyzed by XPS to determine their chemical composition.

Figure 6(a) shows the Si2p core level energy region originating from $\mathrm{Si}$ atoms in the as deposited $\mathrm{SiCO}$ film. The $\mathrm{Si} 2 \mathrm{p}$ spectrum exhibits one peak located at $102.2 \mathrm{eV}$ assigned to $\mathrm{O}_{\mathrm{x}}-\mathrm{Si}-\mathrm{C}_{\mathrm{y}}$ bonds. ${ }^{12-14}$ Figure 6(b) shows $\mathrm{C} 1 \mathrm{~s}$ core level energy regions of the SiCO film. The C1s spectrum exhibits two peaks, located at 283.5 and $285 \mathrm{eV}$. These $\mathrm{C} 1 \mathrm{~s}$ contributions are identified as $\mathrm{C}-\mathrm{Si}$ and $\mathrm{C}-\mathrm{C}$ bonds, respectively. ${ }^{12,15}$ Figure 6(c) shows O1s core level energy regions of SiCO. The O1s spectrum exhibits only one peak, located at $532.5 \mathrm{eV}$ and assigned to oxygen bonded to silicon in the $\mathrm{SiCO}$ environment.

After $\mathrm{H}_{2}$ plasma exposure, the Si2p peak and C1s coming from the SiCO bulk are not observed anymore. A shift to higher binding energy $(104 \mathrm{eV})$ is detected, which is a characteristic of the $\mathrm{Si}-\mathrm{O}_{4}$ environment. ${ }^{7}$ While the $\mathrm{C} 1 \mathrm{~s}$ spectrum shows a peak located at $285 \mathrm{eV}$ assigned to $\mathrm{C}-\mathrm{C}$ bonds coming from carbon contamination after air exposure. A shift of the $\mathrm{O} 1 \mathrm{~s}$ spectrum to $533.5 \mathrm{eV}$ also confirms an important surface oxidation.

Notice that fluorine (not shown) is also detected on the XPS survey spectra after $\mathrm{H}_{2}$ plasma, revealing the presence of this species at the top surface probed by XPS. The fluorine detected in small amount $(<3 \%)$ comes from the reactor walls.

Figure 7 shows that the pristine $\mathrm{SiCO}$ is composed of $37 \%$ silicon, $48 \%$ oxygen, and $15 \%$ carbon (13\% C-Si and $2 \% \mathrm{C}-\mathrm{C})$. After the hydrogen plasma process, the SiCO* film is oxidized $(60 \% \mathrm{O}$ and $40 \% \mathrm{Si})$ at the surface probed by XPS. Compared to the pristine film, the main difference after $\mathrm{H}_{2}$ plasma exposure is the important surface oxidation. Indeed, the $\mathrm{SiCO}^{*}$ film is fully oxidized at the surface probed by XPS.

The trend observed on the SiCO* film is similar to the SiN film exposed to $\mathrm{H}_{2}$ plasma. ${ }^{7}$ Indeed, it has been reported that the $\mathrm{SiN}^{*}$ film is fully oxidized at the surface probed by XPS after $\mathrm{H}_{2}$ plasma (using similar plasma conditions). ${ }^{7}$

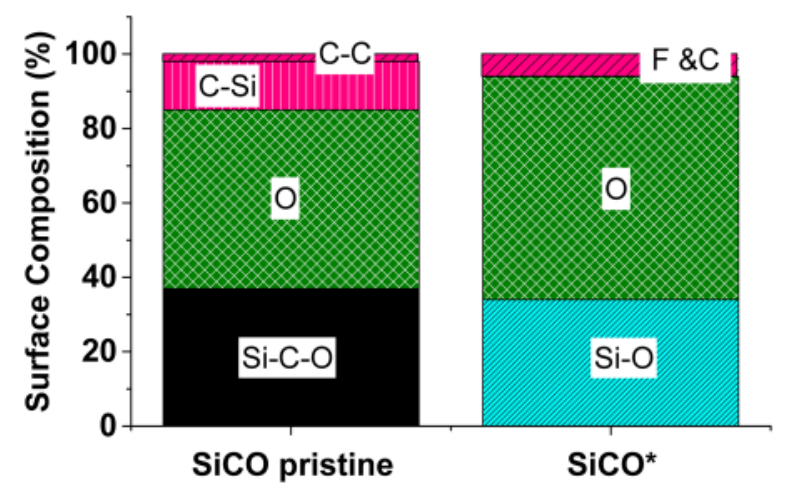

FIG. 7. SiCO as deposited and $\mathrm{SiCO} *$ surface composition determined by XPS. 


\section{Film characterization by infrared spectroscopy}

Figure 8 shows the FTIR data of SiCO before and after $\mathrm{H}_{2}$ plasma exposure in the $600-1700 \mathrm{~cm}^{-1}$ range (no peaks are detected between 1700 and $4000 \mathrm{~cm}^{-1}$ ). The spectra are characterized by different absorption bands assigned to Si-C stretching and $\mathrm{Si}-\mathrm{C}$ bending vibration modes, centered at 800 and $1000 \mathrm{~cm}^{-1}$, respectively. ${ }^{14-16}$

Peaks located at 820 and $1040-1200 \mathrm{~cm}^{-1}$ are also observed and assigned to Si-O-Si stretching in the longitudinal and transverse optical (LO-TO) modes, and the Si-O-Si asymmetric stretching in the TO mode, ${ }^{17}$ respectively.

After $\mathrm{H}_{2}$ plasma exposure, the SiCO* T-FTIR spectrum exhibits similar vibration bands as that of the pristine film (Fig. 8). But, Si-C peak intensity decrease is observed which is in good agreement with XPS analyses previously described.

However, the MIR-FTIR spectrum of the as deposited film $\mathrm{SiCO}$ with or without $\mathrm{H}_{2}$ plasma exposure shows different vibration bands (Fig. 9). The main difference is the presence of a new peak of the Si-H stretching at $2210 \mathrm{~cm}^{-1}$ after $\mathrm{H}_{2}$ exposure. ${ }^{18}$ This indicates higher $\mathrm{H}$ dose implanted in the SiCO* film after $\mathrm{H}_{2}$ plasma exposure.

An additional wide vibration band of $3000-3700 \mathrm{~cm}^{-1}$ is also detected after $\mathrm{H}_{2}$ plasma exposure. This vibration band is assigned to hydroxyl $(-\mathrm{OH})$ bonds. ${ }^{18}$

In this study, we have shown that the $\mathrm{SiCO} *$ film modification depth can be controlled by plasma parameters like bias voltage. Indeed, with an increase of the bias voltage, a thicker SiCO* film damage thickness is measured after HF dip. This $\mathrm{SiCO}^{*}$ film damage by $\mathrm{H}_{2}$ plasma is characterized by carbon depletion in the $\mathrm{SiCO}^{*}$ film, oxidizing the film with important $\mathrm{Si}-\mathrm{H}$ and $\mathrm{Si}-\mathrm{OH}$ bonds' formation.

In a previous study, we have demonstrated that the presence of higher hydrogen concentration $(\mathrm{Si}-\mathrm{H}$ and $\mathrm{N}-\mathrm{H}$ bonds) in the silicon nitride film after $\mathrm{H}_{2}$ plasma ( $\mathrm{SiN}^{*}$ ) is responsible for the higher etch rate. ${ }^{5,6}$ Our experimental results suggest different mechanisms.

Indeed, Fig. 10(a) shows that the Si-H peak intensity is the same when the SiCO film is exposed to $\mathrm{H}_{2}$ plasma with a bias voltage of 250 and $400 \mathrm{~V}$. While in this case, the SiCO* film consumption by HF dip is estimated at 10 and $16 \mathrm{~nm}$, respectively. Contrary to the study performed on the silicon nitride film, this result shows that $\mathrm{Si}-\mathrm{H}$ bonds cannot explain, at the first order, the higher $\mathrm{SiCO}^{*}$ film consumption. This carbon depletion is correlated with important $\mathrm{SiOH}$ bonds observed in Fig. 10(a). The intensity of these $\mathrm{SiOH}$ bonds is all the more important that the bias voltage is high.

Therefore, this tends to indicate that this carbon depletion induced by $\mathrm{H}_{2}$ plasma (converting the SiCO film into $\mathrm{SiO}_{\mathrm{x}} \mathrm{H}_{\mathrm{y}}$ film) is responsible for the higher etch rate at the first order when $\mathrm{SiCO}^{*}$ is dipped in liquid phase HF.

\section{Application to patterned wafer}

The efficiency of the new etch method to remove the modified SiCO film on pattern structures has been evaluated using the stack described in Fig. 1.

$\mathrm{H}_{2}$ plasma operating conditions have been adjusted to target $13 \mathrm{~nm}$ silicon nitride film removal (targeting 30\% over etch). After $\mathrm{SiCO}^{*}$ film modification by $\mathrm{H}$ ions, $210 \mathrm{~s} 1 \%$ HF dip is performed to fully remove the modified layer.

After $25 \mathrm{~nm}$ silicon germanium epitaxial growth, the cross-sectional transmission electron microscopy (TEM) image (Fig. 11) shows that the silicon germanium interface presents a morphology compatible with correct epitaxial growth. After the epitaxial step, no foot formation is observed while the lateral spacer etching is estimated to be around $2.5 \mathrm{~nm}$. Although in our experimental conditions, epitaxial growth is observed on top of the gate. This is explained by the nonselective long $1 \% \mathrm{HF}$ dip process to the $\mathrm{SiO}_{2}$ hard mask during the $\mathrm{SiCO} *$ removal step.

One solution to overcome this issue is to increase the ion energy and to reduce the HF dip time (as shown in Fig. 12). But, the risk in this case is to induce silicon damage and epitaxial growth defects. Indeed, using $\mathrm{H}_{2}$ plasma conditions of $500 \mathrm{~V}$ and a $60 \mathrm{~s} 1 \% \mathrm{HF}$ dip time, the $\mathrm{SiO}_{2}$ hard mask is still present protecting the top of the gate from epitaxial regrowth (Fig. 12). However, a rough surface is meanwhile observed

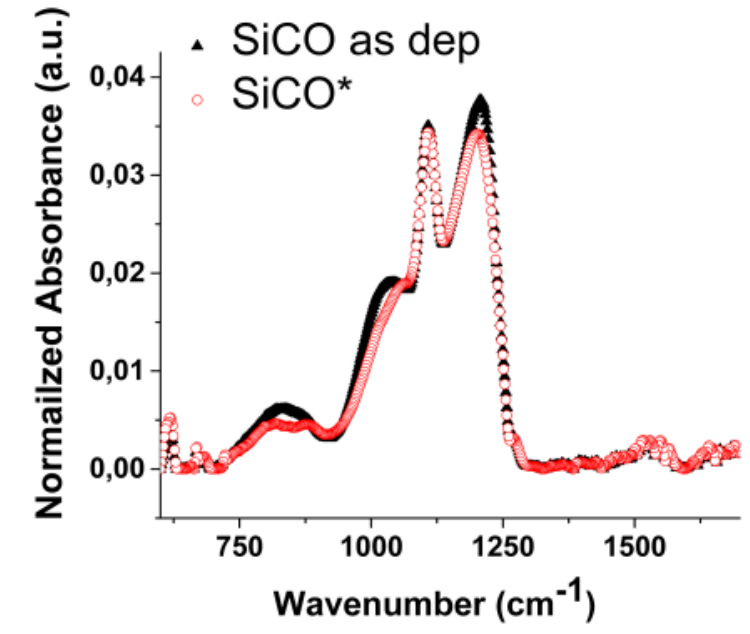

FIG. 8. T-FTIR spectra comparison of the SiCO film before and after $\mathrm{H}_{2}$ plasma performed in an ICP etch tool.

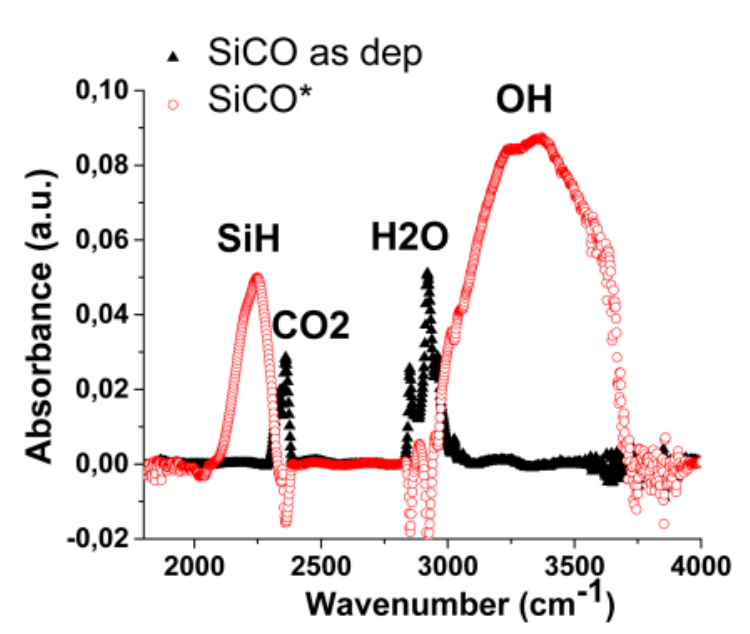

FIG. 9. MIR-FTIR spectra comparison of $\mathrm{SiCO}$ as deposited and after $\mathrm{H}_{2}$ ion implantation performed in an ICP. 

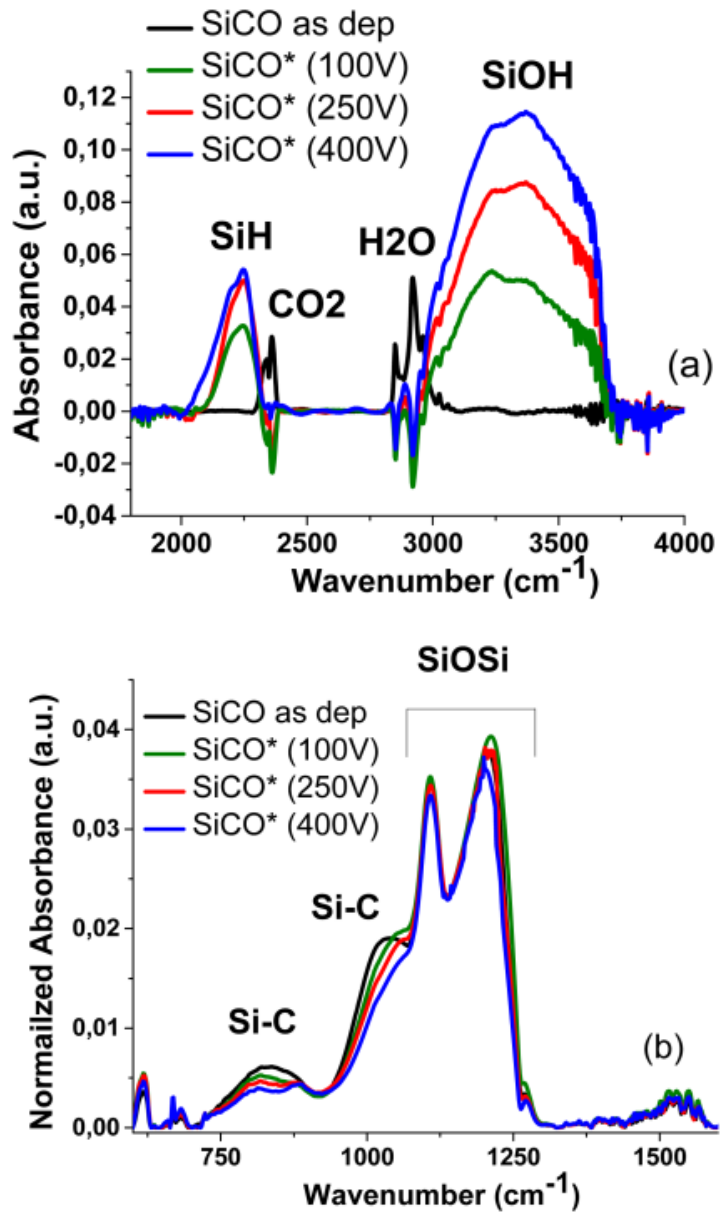

FIG. 10. MIR-FTIR (a) and T-FTIR (b) spectra comparison of SiCO films as a function of bias voltage in the $\mathrm{H}_{2}$ plasma.

which is a characteristic of silicon damage occurring during the $\mathrm{H}_{2}$ modification step.

Finally, based on these results, the most appropriate approach would be to replace $\mathrm{SiO}_{2}$ or to add another hard

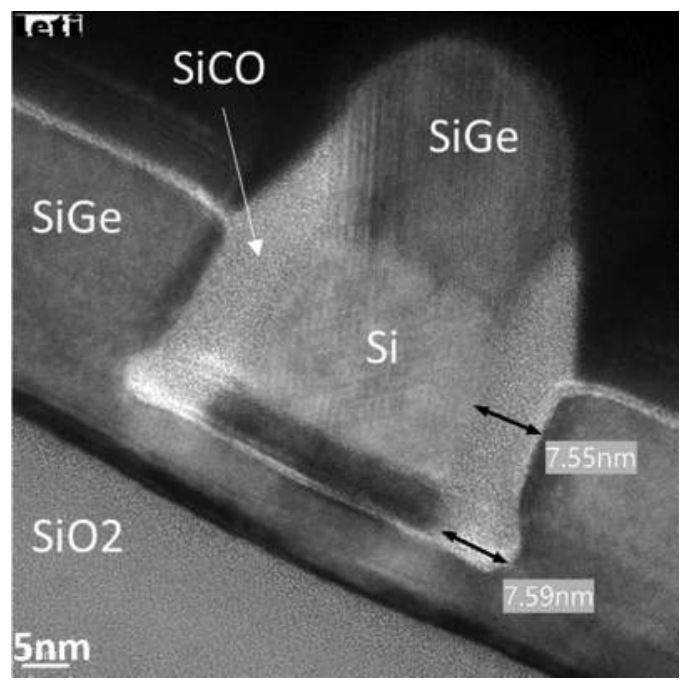

FIG. 11. TEM view after $\mathrm{SiCO}$ spacer etching using $\mathrm{H}_{2}$ plasma $(400 \mathrm{~V})$ followed by a 210 s $1 \%$ HF dip and SiGe epitaxial growth.

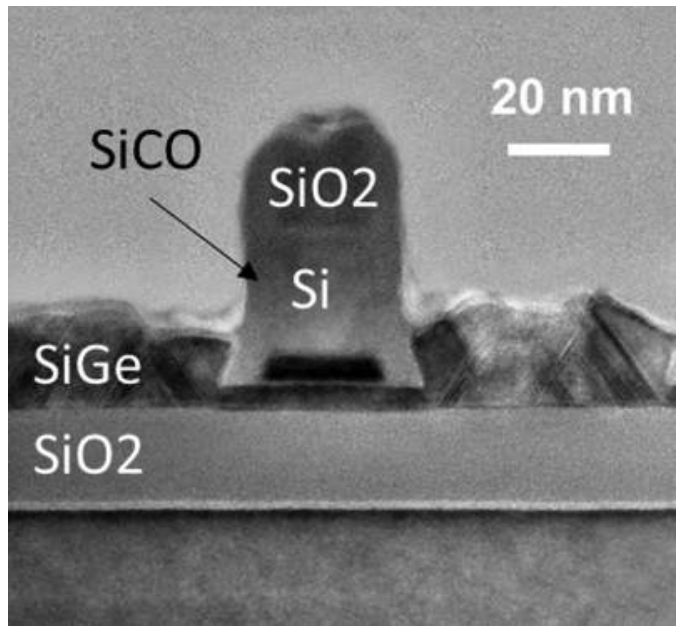

FIG. 12. TEM view after $\mathrm{SiCO}$ spacer etching using $\mathrm{H}_{2}$ plasma $(500 \mathrm{~V})$ followed by a $60 \mathrm{~s} \mathrm{HF}$ dip $1 \%$ and SiGe epitaxial regrowth.

mask on top of $\mathrm{SiO}_{2}$ that is less sensitive to $\mathrm{HF}$ dip, for instance, a silicon nitride hard mask.

\section{CONCLUSION}

In this paper, we investigated $\mathrm{SiCO}$ film etching by a combination of $\mathrm{H}$ ion implantation performed in a conventional plasma etch tool (ICP) followed by a removal step of this modified layer using HF-based wet cleaning.

It has been shown that the $\mathrm{SiCO}^{*}$, modified by $\mathrm{H}_{2}$ plasma, can be fully removed on the blanket wafer by $\mathrm{HF}$ wet cleaning, while the pristine $\mathrm{SiCO}$ is barely etched.

A precise control of the $\mathrm{SiCO} *$ film damage thickness can be tuned by playing on the operating conditions like bias voltage.

It has been demonstrated that the $\mathrm{H}_{2}$ plasma exposure leads to SiCO film oxidation with important $\mathrm{Si}-\mathrm{H}$ and silanol group formation. The carbon depletion observed after $\mathrm{H}_{2}$ plasma (converting the $\mathrm{SiCO}$ film into the $\mathrm{SiO}_{\mathrm{x}} \mathrm{H}_{\mathrm{y}}$ film) is responsible for the higher etch rate at the first order when $\mathrm{SiCO}^{*}$ is dipped in liquid phase HF.

Application on pattern revealed that this approach offers an interesting alternative way to conventional fluorocarbonbased chemistries. Indeed, after $\mathrm{H}_{2}$ plasma followed HF dip, the SiCO spacer can be etched without underneath film modification, no foot formation, and less than $3 \mathrm{~nm}$ lateral $\mathrm{SiCO}$ consumption. A consumption of the $\mathrm{SiO}_{2}$ hard mask (not compatible with the long HF dip time) has also been observed. Therefore, a trade-off has to be found between the bias voltage and the HF dip time. Otherwise, the replacement of the hard mask by a film less sensitive to the HF dip would be an interesting alternative.

${ }^{1}$ H. Niebojewski, C. Le Royer, Y. Morand, M. A. Jaud, O. Rozeau, E. Dubois, and T. Poiroux, IEEE Euro SOI Conference, October 2013 (IEEE SOI, Monterey, 2013).

${ }^{2}$ O. Weber et al., Symposium on VLSI Technology (2015), pp. T168-T169. ${ }^{3}$ F. Deprat et al., Microelectron. Eng. 167, A1 (2017).

${ }^{4} \mathrm{~V}$. Lu et al., International Conference on Solid State Devices and Materials (SSDM), Sapporo, September 2015 (SSDM, Sapporo, 2015). 
${ }^{5}$ N. Posseme, O. Pollet, and S. Barnola, Appl. Phys. Lett. 105, 051605 (2014).

${ }^{6}$ V. Ah Leung, O. Pollet, N. Posseme, M. Garcia-Barros, N. Rochat, C. Guedj, G. Audoit, and S. Barnola, J. Vac. Sci. Technol. A 35, 021408 (2017).

${ }^{7}$ N. Posseme, V. Ah Leung, O. Pollet, C. Arvet, and M. Garcia-Barros, J. Vac. Sci. Technol. A 34, 061301 (2016).

${ }^{8}$ O. Pollet, N. Posseme, V. Ah Leung, and M. Garcia-Barros, Solid State Phenom. 255, 69 (2016).

${ }^{9}$ D. Benoit et al., IEEE International Electron Devices Meeting (IEDM), December 2015 (IEDM, WA, 2015), pp. 8.6.1-8.6.4.

${ }^{10}$ N. Rochat, A. Troussier, A. Hoang, and F. Vinet, Mater. Sci. Eng. C 23, 99 (2003).
${ }^{11}$ N. Rochat, M. Olivier, A. Chabli, F. Conne, and G. Lefeuvre, Appl. Phys. Lett. 77, 2249 (2000).

${ }^{12}$ N. Posseme, T. Chevolleau, O. Joubert, L. Vallier, and P. Mangiagalli, J. Vac. Sci. Technol. B 21, 2432 (2003).

${ }^{13}$ N. Posseme, T. Chevolleau, T. David, M. Darnon, O. Louveau, and O. Joubert, J. Vac. Sci. Technol. B 25, 1928 (2007).

${ }^{14}$ H. Miyazaki, Jpn. J. Appl. Phys. 47, 8287 (2008).

${ }^{15}$ J. W. Yi, Y. H. Lee, and B. Farouk, Thin Solid Films 326, 154 (1998).

${ }^{16}$ Y.-W. Koh, K.-P. Loh, L. Rong, A. T. S. Wee, L. Huang, and J. Sudijono, J. Appl. Phys. 93, 1241 (2003).

${ }^{17}$ C. T. Kirk, Phys. Rev. B 38, 1255 (1988).

${ }^{18}$ M. Darnon, T. Chevolleau, T. David, N. Posseme, J. Ducote, C. Licitra, L. Vallier, O. Joubert, and J. Torres, J. Vac. Sci. Technol. B 26, 1964 (2008). 